\title{
Flood and landslide warning based on rainfall thresholds and soil moisture indexes: the HEWS (Hydrohazards Early Warning System) for Sicily
}

\author{
Giuseppina Brigandì $^{1}$, Giuseppe Tito Aronica ${ }^{1}$, Brunella Bonaccorso ${ }^{1}$, Roberto Gueli $^{1}$, and Giuseppe Basile ${ }^{2}$ \\ ${ }^{1}$ Department of Engineering, University of Messina, 98168 Messina, Italy \\ ${ }^{2}$ Regional Civil Protection Department of Sicily, 90141 Palermo, Italy
}

Correspondence to: Giuseppina Brigandì (gbrigandi@unime.it)

Received: 16 December 2016 - Revised: 3 July 2017 - Accepted: 12 July 2017 - Published: 7 September 2017

\begin{abstract}
The main focus of the paper is to present a flood and landslide early warning system, named HEWS (Hydrohazards Early Warning System), specifically developed for the Civil Protection Department of Sicily, based on the combined use of rainfall thresholds, soil moisture modelling and quantitative precipitation forecast (QPF).

The warning system is referred to 9 different "Alert Zones" in which Sicily has been divided into and based on a threshold system of three different increasing critical levels: ordinary, moderate and high.

In this system, for early flood warning, a Soil Moisture Accounting (SMA) model provides daily soil moisture conditions, which allow to select a specific set of three rainfall thresholds, one for each critical level considered, to be used for issue the alert bulletin.

Wetness indexes, representative of the soil moisture conditions of a catchment, are calculated using a simple, spatiallylumped rainfall-streamflow model, based on the SCS-CN method, and on the unit hydrograph approach, that require daily observed and/or predicted rainfall, and temperature data as input. For the calibration of this model daily continuous time series of rainfall, streamflow and air temperature data are used.
\end{abstract}

An event based lumped rainfall-runoff model has been, instead, used for the derivation of the rainfall thresholds for each catchment in Sicily characterised by an area larger than $50 \mathrm{~km}^{2}$. In particular, a Kinematic Instantaneous Unit Hydrograph based lumped rainfall-runoff model with the SCS-CN routine for net rainfall was developed for this purpose.

For rainfall-induced shallow landslide warning, empirical rainfall thresholds provided by Gariano et al. (2015) have been included in the system. They were derived on an empirical basis starting from a catalogue of 265 shallow landslides in Sicily in the period 2002-2012.

Finally, Delft-FEWS operational forecasting platform has been applied to link input data, SMA model and rainfall threshold models to produce warning on a daily basis for the entire region.

\section{Introduction}

In Europe, and especially in Mediterranean regions, as well as in many other temperate areas in the world, floods, flash floods and debris flows are considered the most frequent natural disaster causing damages and economic losses (Hall et al., 2014).

In the recent past, many Italian regions were affected by natural catastrophes caused by these extreme rainfall events (Aronica et al., 2012). These facts led to great focus being given to the prediction and creation of the alert systems to avoid or, at least, to reduce the occurrence of this type of catastrophes.

In Sicily, the "Integrated Multi-Risk Decentralised Functional Centre" (CFDMI) of Regional Civil Protection Department, is in charge for forecasting, warning and alerting flood and landslide events. This Centre issues daily alert bulletins, both for floods and for landslides, for the entire region and provides the technical tools able to support decisions when significant flood and/or landslide events occur, furnishing continuous support for the entire duration of the emergency period. 
To be fully effective, these extreme events have to be forecasted with a sufficient lead time in order to activate all emergency actions. Consequently, the development of a flood/landslide forecasting and warning system is an essential element in regional and national strategies, as it can support the Civil Protection Agencies in the purpose of mitigating damages and safeguarding the security of people. In particular, it can contribute to reduce the risk of flooding and landslide, especially where the structural measures are not fully capable of preventing the devastating impacts of an extreme event.

Several early warning systems for flood and/or landslide have been developed throughout the world. Their architecture mainly depends on the phenomena that have to be analysed (floods, flash floods, debris flows, landslides, etc. ...) and on the size of the catchments under study.

Most of the catchments in Sicily are small, with flashy hydrological response and prone to flash floods formation (Aronica et al., 2012; Camarasa-Belmonte and Butron, 2015). These events, resulting from severe thunderstorms typical of Mediterranean regions, pose a serious risk to people as water depths and velocities can increase within a short time. This implies that the time between the rainfall event and the consequent flooding is short, which makes traditional real-time flood warning systems that rely on monitoring river levels or measuring rainfall, difficult or impossible to implement. In fact, the forecast lead time may not be long enough to allow the use of rainfall-runoff models that transform observed rainfall into runoff. However, for these catchments even very short lead time warnings may be important and useful, and a possible solution is to consider critical values of hydrological precursors relevant to flooding in order to improve the effectiveness of early flood warning. In particular, the use of flood precursors (rainfall thresholds) implemented off-line and compared in real time with observed or predicted rainfall depths results in a practical alternative.

The rainfall threshold approach is usually used by meteorological organisations (i.e. in the US) or by Civil Protection Agencies (i.e. in Italy) to issue flood alerts (Carpenter et al., 1999; Martina et al., 2006). Assessing, in real time, the observed or predicted rainfall with the rainfall threshold, if the rainfall depth is greater than the rainfall threshold depth, then flooding in the catchments is likely. The relationship between the actual rainfall and the rainfall threshold depends on the soil moisture conditions at the beginning of an event (Carpenter et al., 1999; Georgakakos, 2006), that are among the most important hydrological properties affecting flash floods triggering (Norbiato et al., 2008).

In the United States, flash flood warnings and watches are issued by local NWS (National Weather Service) Weather Forecast Offices (WFOs), based on the comparison of Flash Flood Guidance (FFG) values with rainfall amounts. Guidance values are determined by regional River Forecast Centres (RFCs) and provided to local WFOs for flood forecasting and the issuing of flash flood watches and warnings (Carpenter et al., 1999).

Apart from their extensive use in the United States (Carpenter et al., 1999; Georgakakos, 2006) and in Central America (Georgakakos, 2006), in Europe, both the Integrated Project FLOODSite (http://www.floodsite.net) and the European Project HYDRATE (Hydrometeorological data resources and technologies) for effective flash flood forecasting, among others, aimed at assessing the advantage for using the rainfall thresholds approach as an alternative to the traditional methods in the case of flash floods (Martina et al., 2006).

In the hydrologic literature, several approaches are currently available for deriving rainfall thresholds for flooding. Among these, distributed (Norbiato et al., 2008; Martina et al., 2006; Amadio et al., 2004; Rabuffetti and Barbero, 2005) or lumped (Brigandì, 2009; Brigandì and Aronica, 2009; Georgakakos, 2006; Carpenter et al., 1999) rainfall-runoff models are able to use distributed rainfall input and to exploit information about catchment morphometry.

Over recent years, the link between rainfall and landslides has been the focus of many studies. The analytical approaches, which can be found in the specific technical literature, differ greatly in terms of methodology and formulation. Empirical approaches to forecast the occurrence of rainfallinduced shallow landslide also rely upon the definition of rainfall threshold (Aleotti, 2004; Guzzetti et al., 2007). Two general approaches for identifying thresholds are currently available: an empirical approach based on the analysis of rainstorm characteristics producing landslide, and a physical approach based on modelling the hydrological phenomena and slope stability.

In Italy, several approaches have been developed to derive rainfall thresholds for landslide. The Decentralised MultiRisk Functional Centre of Calabria region, for example, implemented the hydrological FLAIR model (Forecasting of Landslides Induced by Rainfall) originally developed by Sirangelo and Versace (2002), which, starting from rainfall analysis, allows the critical triggering threshold to be identified. The model is based on the identification of a mobility function that links the occurrence of a slope movement to the antecedent rainfall. Brunetti et al. (2010) proposed, instead, an objective method for the definition of empirical rainfall thresholds based on a statistical frequency approach to derive regional rainfall thresholds for the Region of Abruzzo, and on a Bayesian inference method to establish national rainfall thresholds for Italy. Moreover, for the Umbria Decentralised Functional Centre, Berni et al. (2009) have implemented an alert system for floods and landslide warning based on a hydrometric and rainfall thresholds set of three different increasing critical levels according to the expected ground effects.

In the present paper, the early warning system presented is based on the use of rainfall thresholds derived both for floods and for landslides. However, for flood warning, rain- 
fall threshold estimation is part of a more complex warning chain. Taking into account that soil moisture conditions play a very important role in flood formation, the procedure is based on the combined use of rainfall thresholds, soil moisture conditions modelling and forecasted/measured rainfall.

The entire early warning system, named HEWS, is based on the integration of large data sets, specialised modules to process the data, and open interfaces to allow easy integration of existing modelling capacities. For the latter aim, the DelftFEWS open data handling platform has been here adopted.

\section{HEWS}

\subsection{HEWS general architecture}

The "Integrated Multi-Risk Decentralised Functional Centre" (CFDMI) issues each day alert bulletins, both for floods and landslides, for the entire Sicily region by using HEWS (Hydrohazards Early Warning System), developed by the Department of Engineering of the University of Messina.

This system, developed for hydrohazards, collects data such as rainfall forecasts, precipitation and temperature measurements, etc. In addition, it incorporates a web-based information platform, the Delft-FEWS operational forecasting platform, which serves as a central hub for the submission and overview of data. It links input data and developed models to produce warning bulletins on a daily basis.

The developed warning system is composed of several modules that allow to promptly recognise a situation of potential risk for floods and/or landslides throughout the territory.

To facilitate the warning communication, Sicily, as well as all other Italian regions, has been divided into several "Alert Zones" (AZs), that are portions of the territory considered hydrological and geomorphological homogeneous, i.e. characterised by a similar response to flood and landslide events.

As shown in Fig. 1, the island is actually divided into nine Alert Zones (identified by the letters A-I), defined considering local climate, geomorphologic and hydrologic characteristics, as well as administrative boundaries.

In the daily alert bulletin (see Fig. 2) each Alert Zone (AZ) is characterised by different colours that correspond to different alert levels according to the expected criticity. In particular, four possible alert levels can be identified: green, yellow, orange and red. Each alert level is associated to a welldefined critical level: quiet (green colour), ordinary condition (yellow colour), moderate risk condition (orange colour) and high risk condition (red colour). Moreover, each alert level corresponds to a specific activation phase. In particular, green colour corresponds to the "generic vigilance" phase. The other three colours are, instead, representative of increasing activities: in yellow alert level ("Attention" phase) the emergency office is in a warm-up phase; orange alert level corresponds to a "Pre-Alarm" phase and, finally, red alert level

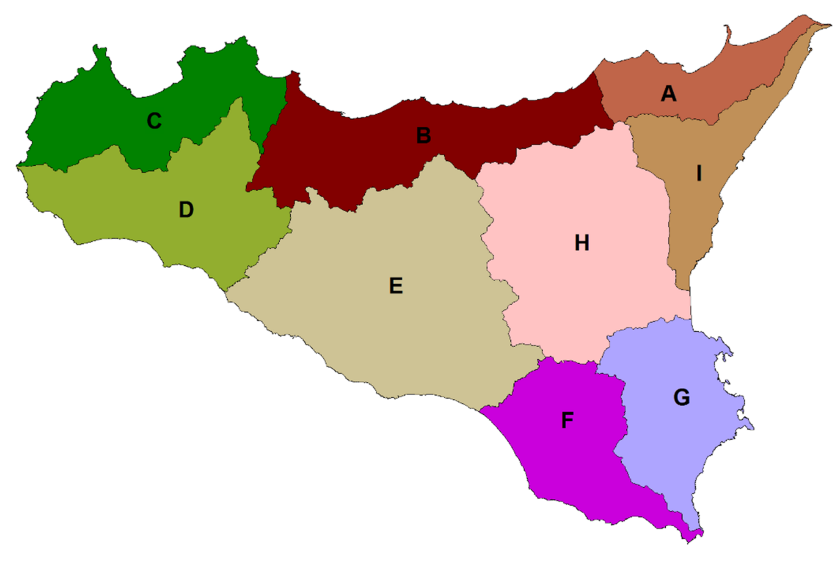

Figure 1. Layout of Alert Zones for Sicily.

corresponds to the "Alarm" phase which requires the undertaking of civil protection procedures and the notifying of the local population.

The produced maps are published daily and can be accessed (public domain) on the website http://www.regione. sicilia.it/presidenza/protezionecivile/pp/archivio_idro.asp.

In Fig. 3, the modelling structure of HEWS is shown. For each Alert Zone, the Soil Moisture Accounting (SMA) model provides daily soil moisture conditions in a continuous form, while rainfall thresholds, that in the case of flooding are function of the soil moisture conditions estimated at the beginning of the day, are used, both for floods and for landslides, for yellow, orange and red alert levels activation.

In agreement with the Regional Civil Protection Department, rainfall thresholds for floods have been derived for each one of 84 catchments in Sicily characterised by an area larger than $50 \mathrm{~km}^{2}$, while rainfall thresholds for landslide have been defined for two groups of Alert Zones.

\subsection{Soil Moisture Accounting model}

As it is widely recognised in the scientific literature, soil moisture plays an important factor in flood formation, due to the fact that runoff generation is strongly influenced by the antecedent soil moisture conditions of the catchment (Aronica and Candela, 2007). Keeping this in mind, the Soil Moisture Accounting (SMA) model has been developed.

SMA model calculates, at the beginning of a day and for each considered catchment, a wetness index $s_{\mathrm{t}}$, varying from 0 to 1, representative of the soil moisture conditions of the catchment, that is then converted into the correspondent daily Curve Number value.

Daily wetness index values, $s_{\mathrm{t}}$, representative of the moisture conditions of the catchment, are derived using a parsimonious and user-friendly approach based on the IHACRES model (Jakeman and Hornberger, 1993) in a modified form developed by the authors (Brigandì and Aronica, 2009, 2015). It is a simple, spatially-lumped rainfall-streamflow 


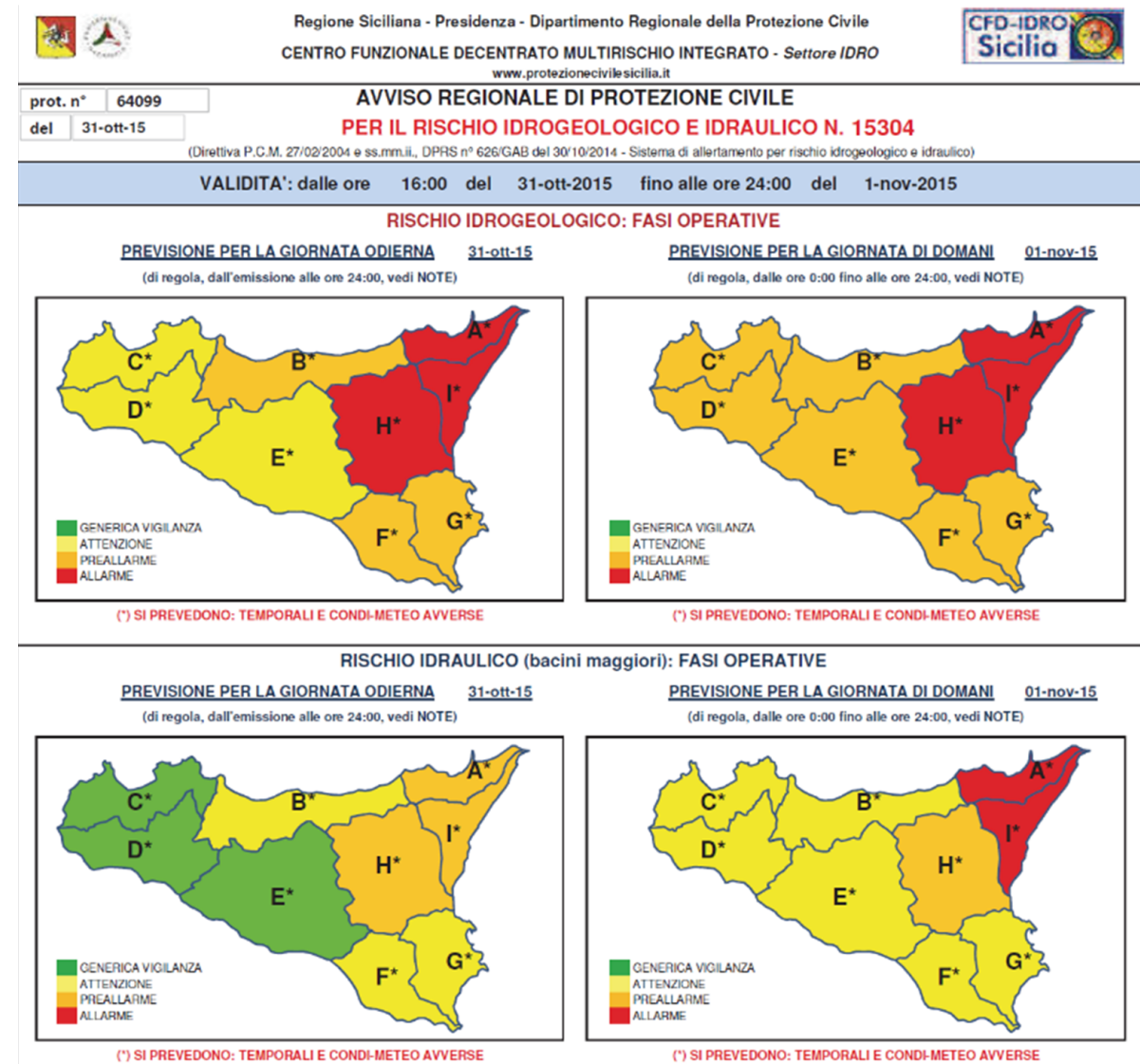

Figure 2. Extract of a daily alert bulletin.

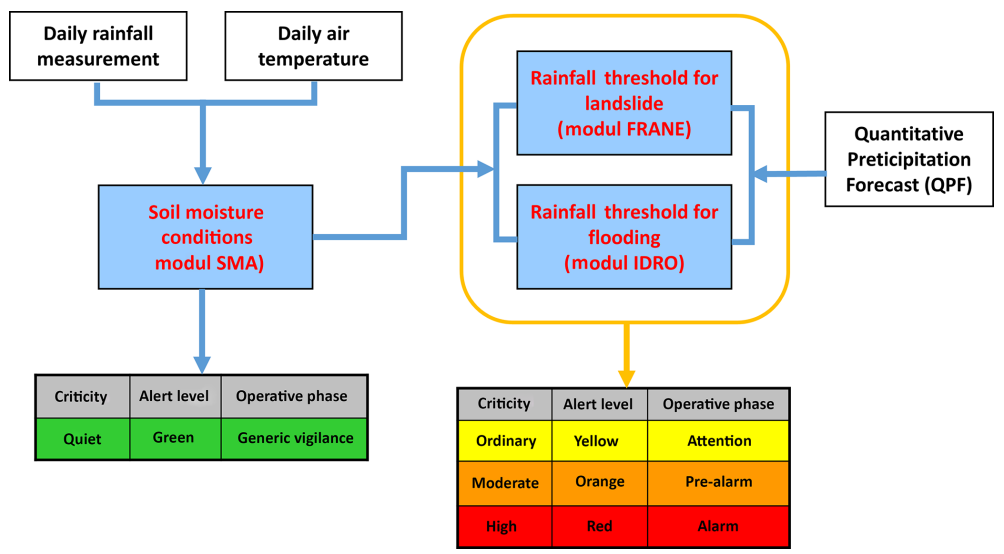

Figure 3. Layout of HEWS model.

model, based on the SCS-CN method and on the unit hydrograph approach that requires only daily continuous time series of rainfall, streamflow and air temperature data as input.

As shown in Fig. 4, the rainfall-streamflow model consists of two modules.

In the first module (the SMA module), whose input are identified by daily rainfall and air temperature data, a non linear loss model, developed by combining the $\mathrm{CN}$ method proposed by Soil Conservation Service (SCS-CN) (USDA, 1986) together with the soil moisture module provided by the IHACRES model, is used to transform total rainfall $P_{\mathrm{t}}$ into effective rainfall $U_{\mathrm{t}}$ : 


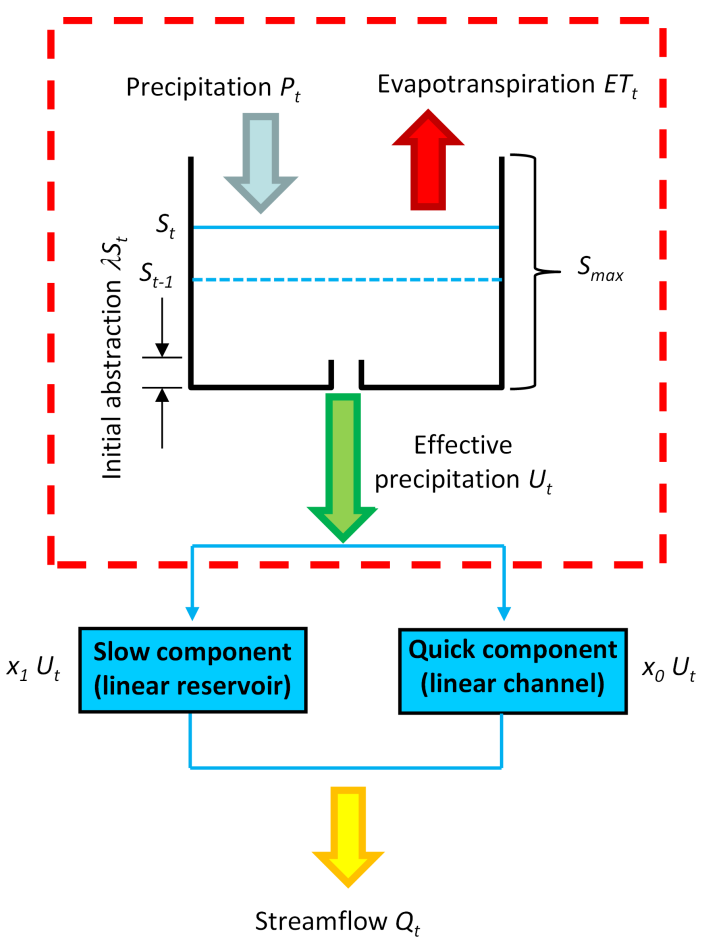

Figure 4. Rainfall-streamflow model scheme (SMA module is highlighted in the red box).

$U_{\mathrm{t}}=\left\{\begin{array}{ll}\frac{\left[P_{\mathrm{t}}-\lambda \cdot a \cdot\left(1-s_{\mathrm{t}}\right)\right]^{2}}{\left[P_{\mathrm{t}}+(1-\lambda) \cdot a \cdot\left(1-s_{\mathrm{t}}\right)\right]} & P_{\mathrm{t}}>\lambda \cdot a \cdot\left(1-s_{\mathrm{t}}\right) \\ 0 & P_{\mathrm{t}} \leq \lambda \cdot a \cdot\left(1-s_{\mathrm{t}}\right)\end{array}\right.$,

$s_{\mathrm{t}}=\frac{P_{\mathrm{t}}}{c}+\left(1-\frac{1}{\tau_{0} \cdot e^{\mathrm{f} \cdot\left(20-T_{\mathrm{t}}\right)}}\right)$

where $\lambda$ is the initial abstraction parameter, $f\left({ }^{\circ} \mathrm{C}^{-1}\right)$ is the temperature modulation factor, $\tau_{0}$ is the drying rate value for $T=20^{\circ} \mathrm{C}, c$ is a parameter chosen to constrain the volume of effective rainfall to equal runoff and and $a$ is the scaling factor. They are the five parameters requiring calibration.

The wetness index $s_{\mathrm{t}}$, which depends both on precipitation $P_{\mathrm{t}}$ and air temperature $T_{\mathrm{t}}$ is also used to calculate the potential maximum retention $S_{\mathrm{t}}$ of the SCS-CN method in a continuous form by means of the following relationship between the parameter $S_{\mathrm{t}}(\mathrm{mm})$ and $s_{\mathrm{t}}$ (Brocca et al., 2009a, b):

$S_{\mathrm{t}}=a \cdot\left(1-s_{\mathrm{t}}\right)$.

The daily Curve Number value $\mathrm{CN}_{\mathrm{t}}$ is then easily calculated through the well known relationship:

$S_{\mathrm{t}}=254 \cdot\left(\frac{100}{\mathrm{CN}_{\mathrm{t}}}-1\right)$.

In the second module of the rainfall-streamflow model, a linear convolution of effective rainfall is then performed using a total unit hydrograph whose configuration of conceptual elements (linear reservoirs and/or channels) in parallel and/or in series, is chosen based on the specific features of the catchments under investigation.

According to the main characteristics of the catchments under study, the chosen configuration consists in one parallel channel and reservoir, corresponding to "quick" and "slow" components of runoff respectively.

For the calibration of the rainfall-streamflow model, daily time series of rainfall, streamflow and air temperature data of 69 stations covering the period from 1921 to 2013 and published by "Osservatorio delle Acque della Regione Sicilia" were analysed. In particular, only those stations where 10 years of consecutive data were available, were selected and used for calibration (six years) and validation (four years).

More specifically, Monte Carlo simulation technique was used to generate with a sample size of $10^{6}$. Finally, the observed and simulated runoff was compared using the NashSutcliffe Efficiency, both in the calibration and the validation stage.

\subsection{Rainfall threshold for floods}

The rainfall threshold approach is usually used to issue alert bulletins by comparing the rainfall thresholds derived offline versus the observed or predicted rainfall depth. If, for a fixed critical level, the rainfall depth is greater than the rainfall threshold depth, then the expected ground effect for that level is likely. The relationship between the actual rainfall and the rainfall threshold depends on the soil moisture conditions at the beginning of the event and on the temporal evolution of the rainstorm. In other words, the rainfall thresholds approach provides a simple tool that allows one to forecast whether a predicted or observed rainfall distribution could produce, for a fixed critical cross section along the river, the critical discharge.

Taking into account that we are dealing with small/medium catchments, ungauged or poorly gauged, rainfall thresholds for HEWS have been derived by solving the hydrologic inverse problem, specifically using an Instantaneous Unit Hydrograph based lumped rainfall-runoff model with the SCS-CN routine for net rainfall (Brigandì, 2009; Brigandì and Aronica, 2009). This approach has been chosen because of its simplicity and particularly because of the small number of parameters that need to be estimated.

Figure 5 shows the structure of the implemented code. When the critical discharge is defined and assumed as input to the model, the code has to solve two phases: the first one performs the rainfall-runoff transformation through the SCS-CN technique, whilst the second one carries out the convolution. This latter phase is not solvable in closed form, so we therefore employ a numerical procedure for minimization of an objective function. 


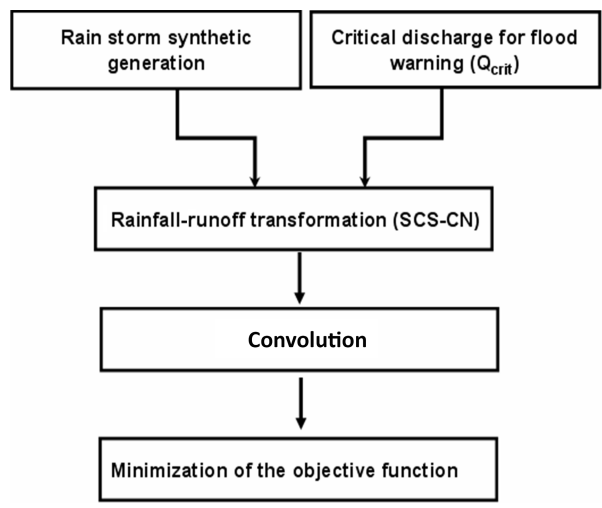

Figure 5. Layout of the procedure for deriving rainfall thresholds for floods.

For this rainfall-runoff transformation, it is not possible to apply the SCS-CN in its classical form, because it is a cumulative model and consequently is not possible to take account of the temporal variation of the rainfall. Hence, in order to overcome this limitation, the SCS dynamic approach has been used (Chow et al., 1988).

By extension of the classical method, the time distribution of the cumulative abstraction $F(t)$ within a storm can be found as follows:

$F(t)=\left\{\begin{array}{ll}\frac{S \cdot[P(t)-\lambda \cdot S]}{[P(t)+\lambda \cdot S]} & P(t)>\lambda \cdot S \\ 0 & P(t) \leq \lambda \cdot S\end{array}\right.$,

where $P(t)$ is the cumulative total rainfall at time $t$ during the event, and $S$ is the potential maximum retention.

The cumulative excess rainfall $U(t)$ at time $t$ can be estimated as follow:

$U(t)=\left\{\begin{array}{ll}P(t)-F(t)-\lambda \cdot S & P(t)>\lambda \cdot S \\ 0 & P(t) \leq \lambda \cdot S\end{array}\right.$.

To solve the hydrologic inverse problem it is necessary also to know the temporal evolution of the rainstorm. The results are strongly influenced by both the adopted model structure and the input hyetograph shape. In order to overcome the limitation due to the lack of sufficient records to produce statistically meaningfully results, synthetic events are generated, totally stochastic for duration and total rainfall, but with well defined hyetograph shapes derived on the basis of the available historical records (Bonaccorso et al., 2017).

When synthetic rainfall is generated, for each duration of rainfall, the code provides several pairs of discharge-height values. Among all the generated pairs of height-discharge, only the couples for which a fixed objective function, based on the comparison, for each generated synthetic event, between the critical discharge $Q_{\mathrm{cr}}$ (defined as input to the system) and the calculated discharge $Q_{\text {sim,p }}$, is smaller than a set tolerance $\varepsilon$ are considered.

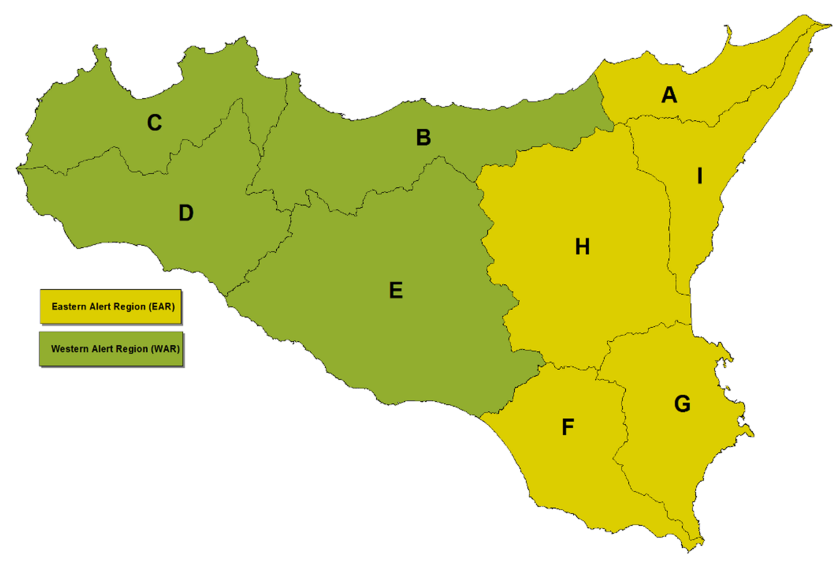

Figure 6. Alert Regions for landslide warning (as proposed by Gariano et al., 2015).

The objective function is here defined as follow:

$\left(Q_{\text {cr }}-Q_{\text {sim }, \mathrm{p}}\right)^{2}<\varepsilon=1 \times 10^{-5}$

where $\varepsilon$ is assumed to be equal to 0.00001 .

Input requested by the code for deriving a rainfall threshold are the $\mathrm{CN}$ and the critical discharge values. This latter parameter is a target value identified by the disaster manager in function of the actions subsequent to the activation of one of the three alert levels considered (yellow, orange, red).

Critical discharges can be calculated either through historic information or through numerical modelling. In this application, upon agreement with the Civil Protection Regional Department, critical discharges for each catchment under consideration were defined through the return period concept. In particular, a return period to correspond respectively with 5 (ordinary condition), 10 (moderate risk condition) and 20 (high risk condition) years was chosen for each critical level considered. These values have been determined following the approach proposed by Bonaccorso et al. (2017).

In particular, a Monte Carlo approach was implemented for deriving, for each considered catchment, flood frequency curves (FFC, i.e. relationship between flood quantiles and related return periods) for estimating the discharge correspondent to the selected return periods. The procedure applied for deriving FFC is based on a combination of statistical methods for deriving the design storms and simulation techniques, through a rainfall-runoff model, to generate synthetic hydrographs (Bonaccorso et al., 2017).

For each one of the 84 considered catchments, once the critical discharges have been defined for each alert level, a set of three rainfall threshold curves has been calculated (respectively for the yellow, orange and red alert level activation) for each possible $\mathrm{CN}$ value (variable from 1 to 99 ).

The choice of the appropriate set of the three rainfall thresholds, that has to be used for the comparison with the forecasted rainfall depth in order to produce the bulletin for 

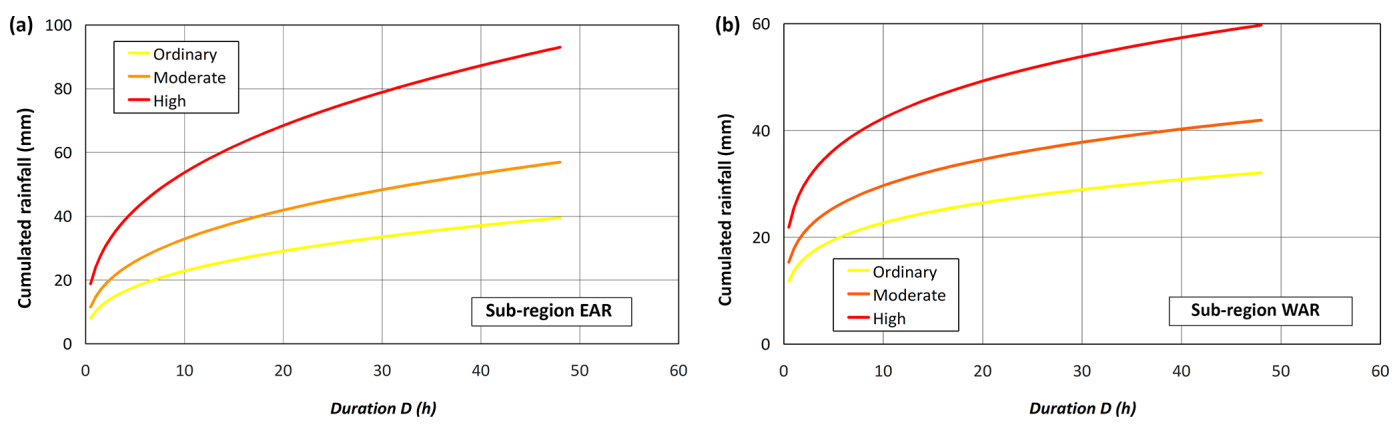

Figure 7. Empirical rainfall thresholds for landslides.

flood warning, depends on the soil moisture conditions at the beginning of the day, represented by the $\mathrm{CN}$ value coming from the SMA module.

\subsection{Rainfall threshold for landslides}

The rainfall threshold approach, in its empirical formulation, has been also implemented in a specific module for warning the occurrence of rainfall-induced shallow landslide. The module performs a comparison between empirical thresholds derived a priori for each Alert Zone (AZ), representative of the possible occurrence of a landslide, with the measured or forecasted rainfall.

Empirical rainfall thresholds for landslides are, in this module, derived following the Gariano et al. (2015) approach, on the basis of a catalogue of 229 rainfall durations and cumulated event rainfall conditions that resulted in 265 shallow landslides in Sicily in the period 2002-2012.

Taking into account that the number of landslide events in each AZ was insufficient to establish reliable rainfall thresholds (Peruccacci et al., 2012), Gariano et al. (2015) grouped the AZs into two broad Alert Regions (ARs), namely: East Alert Region EAR (that groups A, I, H, G and F Alert Zones) covering $45.2 \%$ of the study area, and West Alert Region WAR (that groups B-E Alert Zones) covering $54.8 \%$ of the study area (Fig. 6).

After this grouping, a sufficient number of landslide events was available to establish reliable rainfall thresholds. For each Alert Region, empirical rainfall thresholds were derived adopting the method used by Brunetti et al. (2010) and modified by Peruccacci et al. (2012) as function of different exceedance probabilities.

Upon agreement with the Regional Civil Protection Department, the equations for the $7 \%$ (Ordinary risk condition), $20 \%$ (Moderate risk condition) and 50\% (high risk condition) exceedance probability thresholds were considered to define rainfall thresholds for landslide for each considered Alert Region (Fig. 7).

In order to issue the Alert Bulletin for landslides, the forecasted rainfall depth has to be compared with the empirical rainfall thresholds previously derived. In particular, for A, I,

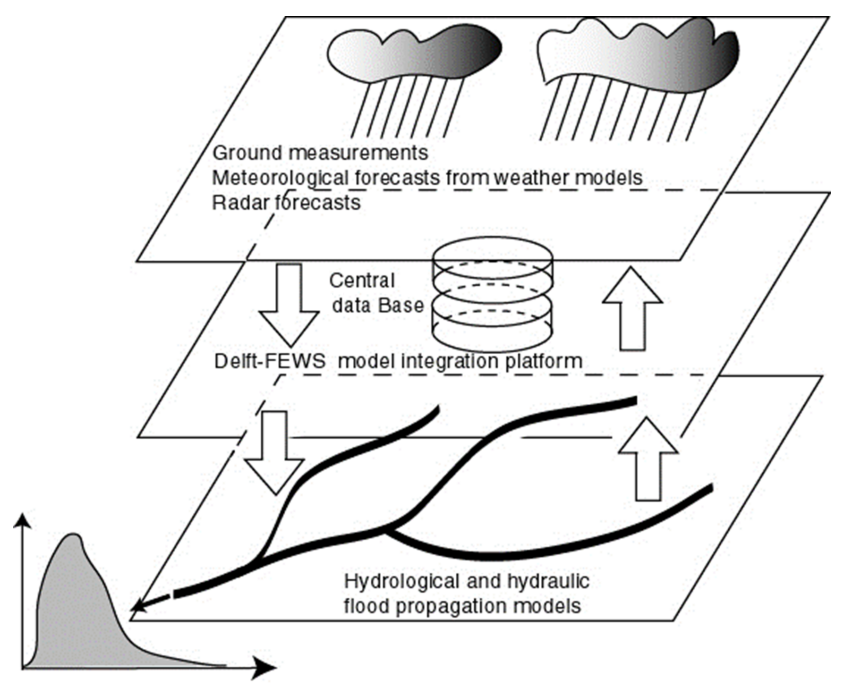

Figure 8. General architecture of the Delft-FEWS open flood forecasting platform (after Verwey et al., 2006).

$\mathrm{H}, \mathrm{G}$ and $\mathrm{F}$ Alert Zones, rainfall thresholds derived for the EAR have to be considered. Vice-versa, rainfall thresholds derived for the WAR have to be analysed if we are dealing with B-E Alert Zones.

\section{Implementation of Delft-FEWS for HEWS}

The Delft-FEWS operational forecasting platform has been used to link input data and the developed models to produce, for each Alert Zone, warning on a daily basis and issue the corresponding Alert Bulletin.

Delft FEWS is a software environment supporting the deployment of operational early warning and forecasting systems. It was specifically designed for addressing the development of an operational platform for water related risk management and provides an open software environment for deploying effective mission-critical operational applications. It allows high flexibility and openness in the integration of third party models and both monitored and forecasted data. It is a data centric data management platform that through its open 


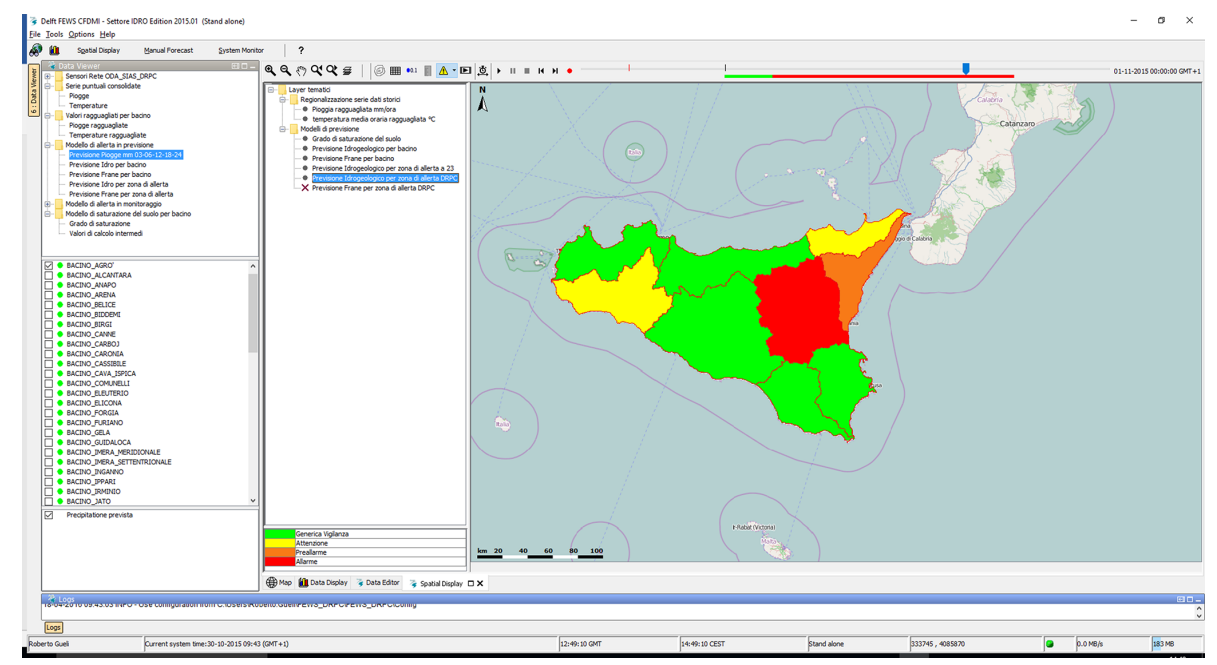

Figure 9. Example of layout coming from Delft-FEWS platform.

interface allows the easy and effective integration of external models (Verwey et al., 2006; Werner et al., 2013). Because of Delft FEWS' effectiveness in linking data and models in real time for providing forecasts on daily basis and nowcasts on event by event basis, it was chosen by the Civil Protection Agency of Sicilian Region for the development of HEWS.

The main goal of this software platform is that of supporting the operational team while providing flood watch and warning services. Delft FEWS allows operational forecasters to provide flood forecasts for the day after, short-term flood nowcasting for the current day, real time monitoring of current flooding events.

The general structure of the software (Fig. 8) is based on a data centric architecture, which allows the interoperability between a wide portfolio of third party models that can cooperate with each other by sharing the same data. More specifically, it provides a wide set of standard tools for importing, handling and exporting location based time series data. This includes modules for data validation, data interpolation, both in time and in space, and for time series data transformation. The Delft FEWS application for the Region of Sicily has been deployed by implementing six main data handling workflows which perform the different steps of the warning process. The operational forecaster can display and edit data in the user interface, import data, run forecasts and analyse and display results.

Data imported off-line are the four parameters of the SMA calibrated model and the rainfall thresholds derived both for flooding and for landslide.

Data that are imported in real time into Delft FEWS and used for issue warning bulletins are, instead, rainfall and air temperature data collected by 264 ground sensors, managed by three different sensor networks, and quantitative precipitation forecast.
After validation of the raw data collected from the ground sensor networks, the data are aggregated and spatially interpolated in order to calculate the average daily rainfall and air temperature time series for each catchment. Those time series are then used as input data for the hydrological balance model that is applied to calculate the soil moisture (wetness index $s_{\mathrm{t}}$ ) and the curve number of each catchment (Module SMA).

The $\mathrm{CN}$ value computed in the previous step is then used to select, for each catchment, the appropriate set of rainfall thresholds that must be used to assess the flood susceptibility.

Finally, forecasted rainfall depth and all the output provided by the model are combined with each other to define the daily Alert Bulletin for each Alert Zone under consideration (Fig. 9).

\section{Conclusions}

In the present paper, the general structure of the early warning system HEWS (Hydrohazards Early Warning System), developed for the "Integrated Multi-Risk Decentralised Functional Centre" (CFDMI) hydrohazards activities of Sicily region has been presented.

HEWS implements a methodology based on the combined use of rainfall thresholds, soil moisture modelling and QPF to issue alert bulletins both for floods and landslides.

To link input data and the developed models to produce warning on a daily basis, for each Alert Zone in which the island has been divided into, the Delft-FEWS operational forecasting platform has been adopted. In particular, six main data handling workflows which perform the different steps of the warning process have been implemented. 
The system is presently being run on the CFDMI platform and it will be under testing until summer 2017. Preliminary tests of the system in Sicily have produced satisfying results, even if the robustness and limits of the methodology may be verified only at the end of the testing period.

Data availability. For the daily rainfall, temperature and discharge data used in this study, readers may refer to Annali Idrologici Parte I and Parte II. They are public data and free available at http://www.acq.isprambiente.it/annalipdf/. Sub-hourly rainfall data are published by Servizio Informativo Agrometeorologico Siciliano (SIAS) and free available at http://www.sias.regione.sicilia.it/ frameset_download.htm.

Competing interests. The authors declare that they have no conflict of interest.

Special issue statement. This article is part of the special issue "Hydro-related hazardous events and their consequences in the Mediterranean area: knowledge management adaptation". It is a result of the 15th Plinius Conference on Mediterranean Risks, Giardini Naxos, Italy, 8-11 June 2016.

Acknowledgements. This study is part of the research activities carried out within the research contract n. F68C13000060008 between Sicilia e - Ricerca SpA and the University of Messina (European Regional Development Fund - PO FESR Sicilia 2007-2013, Linea di intervento 2.3.1. C).

Edited by: A. Loukas

Reviewed by: three anonymous referees

\section{References}

Aleotti, P.: A warning system for rainfall-induced shallow failures, Eng. Geol., 73, 247-265, 2004.

Amadio, P., Mancini, M., Menduni, G., and Ravazzani, G.: Analisi di affidabilità del sistema di preallerta di piena in tempo reale MIMI per il bacino del fiume Arno, Proc. of 29th Convegno di Idraulica e Costruzioni Idrauliche, Trento, Italy, 2004.

Aronica, G. T. and Candela, A.: Derivation of flood frequency curves in poorly gauged Mediterranean catchments using a simple stochastic hydrological rainfall-runoff model, J. Hydrol., 347, 132-142, 2007.

Aronica, G. T., Brigandì, G., and Morey, N: Flash floods and debris flow in the city area of Messina, north-east part of Sicily, Italy in October 2009: the case of the Giampilieri catchment, Nat. Hazards Earth Syst. Sci., 12, 1295-1309, https://doi.org/10.5194/nhess-12-1295-2012, 2012.

Berni, N., Pandolfo, C., Stelluti, M., Ponziani, F., and Viterbo, A.: Operational flood forecasting system of Umbria Region "Functional Centre" - Italy, Geophys. Res. Abstr., EGU2009-9760, 2009.
Bonaccorso, B., Brigandì, G., and Aronica, G. T.: Combining regional rainfall frequency analysis and rainfall-runoff modelling to derive frequency distributions of peak flows in ungauged basins: a proposal for Sicily region (Italy), Adv. Geosci., 44, 1522, https://doi.org/10.5194/adgeo-44-15-2017, 2017.

Brigandì, G.: Il preavviso delle piene in bacini non strumentati attraverso l'uso di precursori idro-pluviometrici, $\mathrm{PhD}$ dissertation, University of Palermo, Palermo, 2009.

Brigandì, G. and Aronica, G. T.: Operational flash flood forecasting chain using hydrological and pluviometric precursors, in: Flood Risk Management: Research and Practice, edited by.: Samuels, P., Huntington, S., Allsop, W., and Harrop, J., 1321-1331, 2009.

Brigandì, G. and Aronica, G. T.: A flash flood early warning system based on rainfall thresholds and daily soil moisture indexes, Geophys. Res. Abstr., 17, EGU2015-11878, 2015.

Brocca, L., Melone, F., Moramarco, T., and Singh, V. P.: Assimilation of Observed Soil Moisture Data in Storm Rainfall-Runoff Modeling, J. Hydraul. Eng., 2, 153-165, 2009a.

Brocca, L., Melone, F., and Moramarco, T.: Antecedent Wetness Conditions based on ERS scatterometer data in support to rainfall-runoff modeling, J. Hydrol., 364, 73-86, 2009b.

Brunetti, M. T., Peruccacci, S., Rossi, M., Luciani, S., Valigi, D., and Guzzetti, F.: Rainfall thresholds for the possible occurrence of landslides in Italy, Nat. Hazards Earth Syst. Sci., 10, 447-458, https://doi.org/10.5194/nhess-10-447-2010, 2010.

Camarasa-Belomonte, A. M. and Butron, D.: Estimation of flood risk thresholds in Mediterranean areas using rainfall indicators: case study of Valencian Region (Spain), Nat. Hazards, 78, 1243 1266, 2015.

Carpenter, T. M., Spefslage, J. A., Georgakakos, K. P., Sweeney, T., and Fread, D. L.: National threshold runoff estimation utilizing GIS in support of operational flash flood warning systems, J. Hydrol., 244, 21-44, 1999.

Chow, V. T., Maidment, D. R., and Mays, L. W.: Applied Hydrology, in: McGraw-Hill International Editions, McGraw-Hill, New York, 1988.

Hall, J., Arheimer, B., Borga, M., Brázdil, R., Claps, P., Kiss, A., Kjeldsen, T. R., Kriaučiūnienė, J., Kundzewicz, Z. W., Lang, M., Llasat, M. C., Macdonald, N., McIntyre, N., Mediero, L., Merz, B., Merz, R., Molnar, P., Montanari, A., Neuhold, C., Parajka, J., Perdigão, R. A. P., Plavcová, L., Rogger, M., Salinas, J. L., Sauquet, E., Schär, C., Szolgay, J., Viglione, A., and Blöschl, G.: Understanding flood regime changes in Europe: a state-of-the-art assessment, Hydrol. Earth Syst. Sci., 18, 2735 2772, https://doi.org/10.5194/hess-18-2735-2014, 2014.

Gariano, S. L., Brunetti, M. T., Iovine, G., Melillo, M., Peruccacci, S., Terranova, O., Vennari, C., and Guzzetti, F.: Calibration and validation of rainfall thresholds for shallow landslide forecasting in Sicily, southern Italy, Geomorphology, 228, 653-665, 2015.

Georgakakos, K. P.: Analytical results for operational flash flood guidance, J. Hydrol., 317, 81-103, 2006.

Guzzetti, F., Peruccacci, S., Rossi, M., and Stark, C. P.: Rainfall thresholds for the initiation of landslides in central and southern Europe, Meteorol. Atmos. Phys., 98, 239-267, 2007.

Jakeman, A. J. and Hornberger, G. M.: How much com-plitexity is warrented in a rainfall-runoff model?, Water Resour. Res., 29, 2637-2649, 1993.

Martina, M. L. V., Todini, E., and Libralon, A.: A Bayesian decision approach to rainfall thresholds based flood warning, $\mathrm{Hy}-$ 
drol. Earth Syst. Sci., 10, 413-426, https://doi.org/10.5194/hess10-413-2006, 2006.

Norbiato, D., Borga, M., Degli Esposti, S., Gaume, E., and Anquetin, S.: Flash flood warning based on rainfall threshold and soil moisture conditions. An assessment for gauged and ungauged basins, J. Hydrol., 362, 274-290, 2008.

Peruccacci, S., Brunetti, M. T., Luciani, S., Vennari, C., and Guzzetti, F.: Lithological and seasonal control of rainfall thresholds for the possible initiation of landslides in central Italy, Geomorphology, 139-140, 79-90, 2012.

Rabuffetti, D. and Barbero, S.: Operational hydro-meteorological warning and real-time flood forecasting: the Piemonte Region case study, Hydrol. Earth Syst. Sci., 9, 457-466, https://doi.org/10.5194/hess-9-457-2005, 2005.
Sirangelo, B. and Versace, P.: Modelli stocastici di precipitazione e soglie pluviometriche di innesco dei movimenti franosi, in: Proc. 23rd Convegno di Idraulica e Costruzioni Idrauliche, Firenze, Italy, 2002.

USDA - US Department of Agricolture: Soil Conservation Service, National Engineering Handbook, Hydrology, Sect. 4, Washington, D.C., 1986.

Verwey, A., Heynert, K., Werner, M., Reggiani, P., van Kappel, B., and Brinkman, J. J.: The potential of the DELFT-FEWS Flood Forecasting Platform for application in the Mekong basin, in: 4th Annual Mekong Flood Forum, Siem Reap, Cambodia, 2006.

Werner, M., Schellekens, J., Gijsbers, P., Van Dijk, M., Van den Akker, O., and Heynert, K.: The Delft-DELFT-FEWS flow forecasting system, Environ. Model. Softw., 40, 65-77, 2013. 